\title{
A cross-sectional study of acute diarrhea in Pudong, Shanghai, China: prevalence, risk factors, and healthcare-seeking practices
}

\author{
J.-X. YU ${ }^{1,2} \dagger$, W.-P. ZHU ${ }^{3} \dagger$, C.-C. YE ${ }^{3,4} \dagger$, C.-Y. XUE ${ }^{3,4}$, S.-J. LAI ${ }^{2}$, \\ H.-L. ZHANG ${ }^{2}$, Z.-K. ZHANG ${ }^{2,5}$, Q.-B. GENG ${ }^{2,6}$, W.-Z. YANG ${ }^{2}$, \\ Q. $\mathrm{SUN}^{3}$ AND Z.-J. LI ${ }^{2} *$ \\ ${ }^{1}$ MOH Key Laboratory of Systems Biology of Pathogens and Dr Christophe Mérieux Laboratory, \\ CAMS-Fondation Mérieux, Institute of Pathogen Biology, Chinese Academy of Medical Sciences \& Peking \\ Union Medical College, Beijing, China \\ ${ }^{2}$ Division of Infectious Disease, Key Laboratory of Surveillance and Early-warning on Infectious Disease, \\ Chinese Center for Disease Control and Prevention, Beijing, China \\ ${ }^{3}$ Research Base of Key Laboratory of Surveillance and Early-warning on Infectious Disease in China CDC, \\ Pudong New Area Center for Disease Control and Prevention, Shanghai, China \\ ${ }_{5}^{4}$ School of Public Health, Fudan University, Shanghai, China \\ ${ }^{5}$ State Key Laboratory for Diagnosis and Treatment of Infectious Diseases, First Affiliated Hospital, \\ School of Medicine, Zhejiang University, Hangzhou, China \\ ${ }^{6}$ State Key Laboratory of Virology, College of Life Sciences, Wuhan University, Wuhan, China
}

Received 30 March 2017; Final revision 2 July 2017; Accepted 21 July 2017;

first published online 23 August 2017

\section{SUMMARY}

Diarrhea is a common cause of morbidity and mortality and the incidence of diarrhea in the world has changed little over the past four decades. To assess the prevalence of and healthcare practices for diarrhea, a cross-sectional study was conducted in Pudong, Shanghai, China. In October 2014, a total of 5324 community residents were interviewed. Respondents were asked if they had experienced diarrhea (defined as $\geqslant 3$ passages of watery, loose, bloody, or mucoid stools within a 24-h period) in the previous month prior to the interview. The monthly prevalence of diarrhea was $4 \cdot 1 \%$ (95\% CI: $3 \cdot 3-4 \cdot 8)$, corresponding to an incidence rate of 0.54 episodes per person-year. The proportion of individuals with diarrhea who sought healthcare was $21 \cdot 2 \%(95 \%$ CI: $13 \cdot 4-29 \cdot 0)$. Diarrhea continues to impose a considerable burden on the community and healthcare system in Pudong. Young age and travel were identified as predictors of increased diarrhea occurrence.

Key words: Diarrhea, epidemiology, healthcare-seeking behavior, prevalence, risk factors.

\section{INTRODUCTION}

Diarrhea is a common cause of morbidity and mortality worldwide, with an estimated loss of $\sim 89 \cdot 5$ million

\footnotetext{
* Author for correspondence: Z. Li, Division of Infectious Disease, Key Laboratory of Surveillance and Early-warning on Infectious Disease, Chinese Center for Disease Control and Prevention, Changbai Rd. 155\#, Changping Dist., Beijing 102206, China. (E-mail: lizhongjiecdc@163.com)

$\uparrow$ These authors contributed equally to this work.

Name of department(s) and institution(s) to which the work should be attributed: Shanghai Pudong New Area Center for Disease Control and Prevention
}

disability-adjusted life years and 1.45 million deaths in $2010[1,2]$, which represents a major obstacle to the achievement of the United Nation's Fourth Millennium Development Goals [3]. China is one of the 15 high-burden countries for diarrhea in the world [4], and a recent national survey estimated that China's incidence rate for acute gastrointestinal illness (diarrhea and vomiting) was 0.56 episodes per person-year in 2010 [5]. However, in Pudong New Area, the largest district of Shanghai city, considerable data gaps exist regarding the risk factors and the burden of diarrhea 
on both the population and the healthcare system. From a public health perspective, these represent important data for planning, implementing and evaluating disease control programs, e.g., the development of recommendations for vaccines and the formulation of food and water hygiene regulations. To this end, a cross-sectional study of diarrhea was conducted in the community of Pudong in October 2014. At the end of year 2014, Pudong had a population of 5.4 million and about $90 \%$ of the population were living in urban areas; the average gross domestic product per capita was 97370 yuan ( US\$ 14000), about twice that of the national average (47 203 yuan) [6].

The purpose of the present study was to measure the prevalence of diarrhea, explore its determinants, and determine the proportion of people who seek healthcare for diarrhea in the community of Pudong.

\section{METHODS}

\section{Study design and sampling procedure}

A complex sampling method was used to recruit survey respondents. Each referral area of the 46 community health centers in Pudong randomly selected one community, and all residents living in the selected community during the year prior to the survey were eligible for the interview. Trained community health workers traveled to the selected communities to conduct face-to-face surveys at several locations (residential areas, kindergartens and children's vaccination clinics) through Monday to Sunday during day time (from 9 A.M. to 5 P.M.) in our study period. Study subjects were recruited at these locations using a convenience (accidental) sampling method, in which community residents close at hand were interviewed. Because of the different methodologies used, the interviews were conducted separately for 2 age strata, e.g., children $<5$ years of age and people $\geqslant 5$ years of age (older children, adolescents and adults) (Fig. 1).

A minimum number of 45 completed interviews from children $<5$ years old and 70 completed interviews from older children, adolescents and adults were required for each selected community based on the total sample size of the study. For children $<5$ years old, a target sample of 2000 was required. This number was calculated based on an assumed monthly prevalence of $12 \%$ for children aged $<5$ years $[5,7]$, with a precision level of $2 \%$, a confidence level of $95 \%$ and a design effect of two. For people $\geqslant 5$ years of age, a target sample of 3000 was required based on an assumed monthly prevalence of 4\% [5], with a $1 \%$ precision level, a $95 \%$ confidence level and a design effect of two.

\section{Data collection}

Standardized questionnaires were used to collect data from the study subjects, which were adapted from previous works of World Health Organization and were modified to suit local context [7]. Diarrhea was defined as $\geqslant 3$ passages of watery, loose, mucoid, or bloody stools within a 24-h period [8]. A 7-day symptom-free interval was used to define a new episode of diarrhea. Surrogate interviews were conducted for the child subjects by interviewing the children's parents or guardians, while subjects $\geqslant 14$ years of age were interviewed directly. The questionnaires included three sets of questions: (i) socio-demographic characteristics, including age, sex, occupation (of parents or guardians for children), ethnic group, educational attainment (of parents or guardians for children), average monthly household income, outof-province travel history in the previous month (defined as going to other parts of China or the rest of the world, of parents or guardians for children), and rotavirus vaccination history for children $<5$ years of age; (ii) characteristics of self-reported diarrhea, including episodes of diarrhea experienced in the previous month, signs/symptoms, and illness duration; and (iii) hospital utilization behavior (defined as consulting a doctor in private clinic or visiting a community health center or hospital) and attitudes of the respondents. For subjects who had experienced more than two episodes of diarrhea, the illness characteristics and healthcare-seeking behavior of the respondents were described and reported for only the most recent episode. Written and informed consent was obtained from all the participants or from the parents/guardian of children before the interviews.

To validate our results, all the interviews were conducted in Mandarin. A pilot study and training courses for the interviewers were conducted before the study began. An inspector was assigned to each site during the study period to review the finished questionnaires for completeness and logical errors and to eliminate duplicate surveys. Ineligible questionnaires were returned to the interviewers for verification or re-investigation. The collected data were entered into EpiData, version 3.1 (EpiData Association, Odense M, Denmark). 


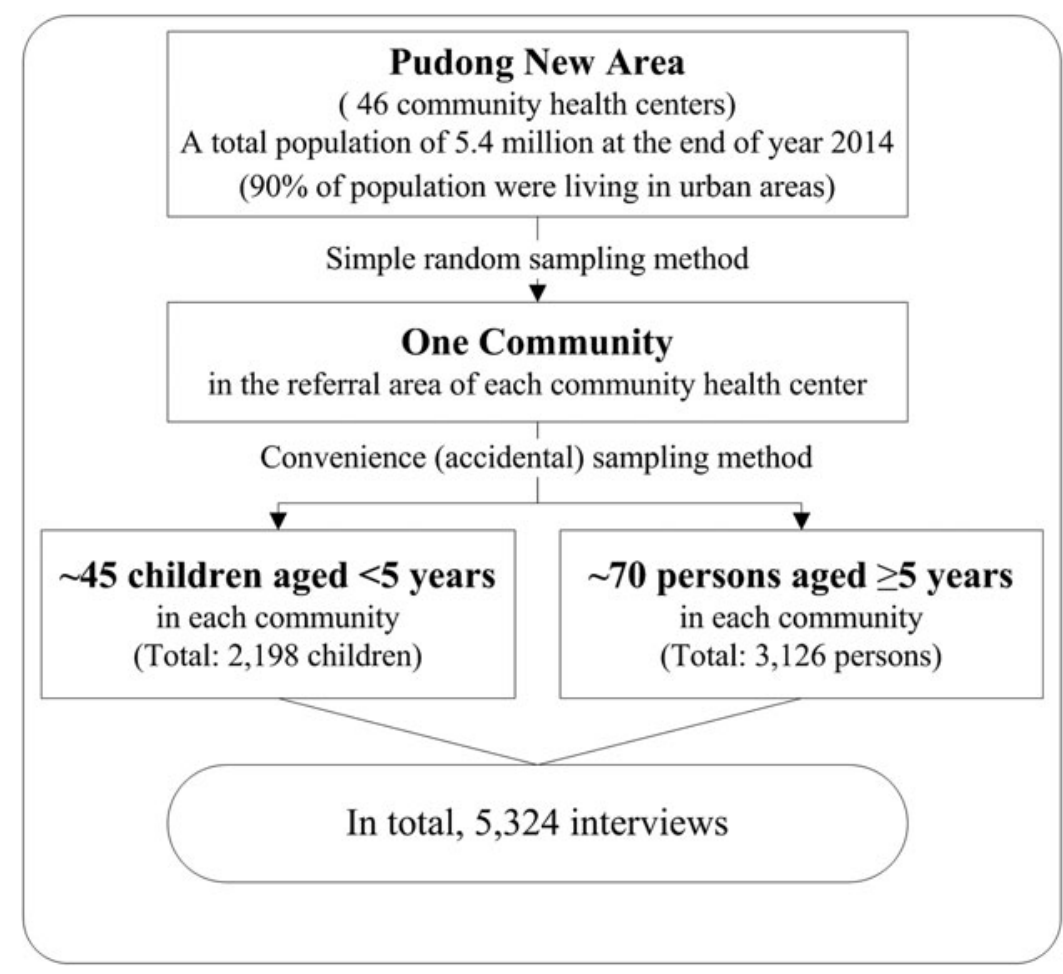

Fig. 1. Schematic diagram of sampling frame for diarrhea survey in Pudong, Shanghai, China, 2014.

\section{Statistical analysis}

All the analyses were conducted in R, version 2.15.3 (R Foundation for Statistical Computing, Vienna, Austria), by using the 'survey' package to adjust for the complex sampling procedures $[9,10]$. The prevalence of diarrhea was calculated as the number of subjects who reported experiencing diarrhea in previous month divided by the total number of subjects interviewed. All analyses were weighted to account for non-response of the studied subjects, according to the age, sex and site distribution of the Pudong population. The estimated incidence rate of diarrhea was calculated using the formulae and method employed by Thomas et al. [11] To compare demographic and epidemiological characteristics, Chi-square tests or Fisher exact tests were used for the categorical variables, and Wilcoxon rank-sum or Kruskal-Wallis tests were used for the continuous variables, as appropriate. Multivariable logistic regression models were used to investigate the predictors of diarrhea occurrence.

\section{RESULTS}

\section{Characteristics of the study respondents}

Between October 2nd and November 3rd 2014, we conducted 5324 interviews in 46 communities in
Pudong. Of these, 2198 interviews were for child subjects aged $<5$ years, and 3126 interviews were with subjects $\geqslant 5$ years of age. The respondents for the child subjects were the children's parents or guardians (grandparents), and some variables, e.g., education level and travel history, were collected for the respondents rather than for the children. The education level of the respondents for the child subjects was significantly lower $(87 \cdot 0 \%$ of these respondents finished primary school or were illiterate) than the educational level of the other respondents $(10.7 \%, P<0.001)$. Out-of-province travel history in the previous month prior to the interview was reported by $20 \cdot 2 \%$ of the study respondents. Thirty-two percent of the respondents for the child subjects reported that their children had received the rotavirus vaccination (Table 1).

\section{Prevalence of diarrhea and healthcare-seeking behavior among individuals with diarrhea}

In total, 231 of the study respondents $(4 \cdot 3 \%)$ reported experiencing at least one newly occurring episode of diarrhea in the previous month prior to the interview. The reported median illness duration of diarrhea was 2 days (range: $1-30$ days), with children aged $<5$ years significantly longer than that of subjects aged $\geqslant 5$ 
Table 1. Characteristics of surveyed respondents in Pudong, Shanghai, China, 2014, stratified by age group

\begin{tabular}{|c|c|c|c|}
\hline \multirow[b]{2}{*}{ Variables } & \multicolumn{2}{|l|}{ Age groups } & \multirow[b]{2}{*}{ No. total $(\%)$} \\
\hline & $\begin{array}{l}\text { No. children } \\
\text { aged }<5 \text { years }(\%)\end{array}$ & $\begin{array}{l}\text { No. persons } \\
\text { aged } \geqslant 5 \text { years }(\%)\end{array}$ & \\
\hline \multicolumn{4}{|l|}{ Gender } \\
\hline Male & $1098(50 \cdot 0)$ & $1555(49 \cdot 8)$ & $2653(49 \cdot 9)$ \\
\hline Female & $1099(50 \cdot 0)$ & $1569(50 \cdot 2)$ & $2668(50 \cdot 1)$ \\
\hline \multicolumn{4}{|l|}{ Educational attainment $^{1}$} \\
\hline Primary school or illiterate & $1892(87 \cdot 0)$ & $335(10 \cdot 7)$ & $2227(42 \cdot 1)$ \\
\hline High school & $80(3 \cdot 7)$ & $1136(36 \cdot 4)$ & $1216(23 \cdot 0)$ \\
\hline College level and above & $203(9 \cdot 4)$ & $1647(52 \cdot 8)$ & $1850(34 \cdot 9)$ \\
\hline \multicolumn{4}{|c|}{ Average monthly household income, (Chinese yuan $)^{2}$} \\
\hline$<3000$ & $379(17 \cdot 3)$ & $744(23 \cdot 9)$ & $1123(21 \cdot 2)$ \\
\hline 3000-9999 & $1030(47 \cdot 1)$ & $1602(51 \cdot 5)$ & $2632(49 \cdot 7)$ \\
\hline $10000-19999$ & $264(12 \cdot 1)$ & $271(8 \cdot 7)$ & $535(10 \cdot 1)$ \\
\hline$\geqslant 20000$ & $91(4 \cdot 2)$ & $73(2 \cdot 3)$ & $164(3 \cdot 1)$ \\
\hline Don’t know & $424(19 \cdot 4)$ & $418(13 \cdot 4)$ & $842(15 \cdot 9)$ \\
\hline \multicolumn{4}{|l|}{ Travel history ${ }^{1}$} \\
\hline Yes & $446(20 \cdot 5)$ & $611(19 \cdot 9)$ & $1057(20 \cdot 2)$ \\
\hline $\mathrm{No}$ & $1731(79 \cdot 5)$ & $2455(80 \cdot 1)$ & $4186(79 \cdot 8)$ \\
\hline \multicolumn{4}{|l|}{ Rotavirus vaccination } \\
\hline Yes & $686(32 \cdot 0)$ & - & - \\
\hline No & $1460(68 \cdot 0)$ & - & - \\
\hline
\end{tabular}

${ }^{1}$ For children aged $<5$ years, the numbers in this column represent data for the children's parents or guardians.

21 US dollar $\approx 6 \cdot 9$ Chinese yuan; An $n$-dash denotes that data were not available.

years ( 3 vs. 2 days, $P<0 \cdot 001)$. The most frequently reported symptoms other than diarrhea was abdominal pain $(n=68,28 \cdot 1 \%)$, followed by fever $(n=29$, $12 \cdot 6 \%)$, fatigue $(n=24,10 \cdot 4 \%)$, vomiting $(n=21$, $9 \cdot 1 \%)$, restlessness $(n=21,9 \cdot 1 \%)$, respiratory symptoms $(n=13,5 \cdot 6 \%)$, and dehydration $(n=4,1 \cdot 7 \%)$.

The estimated monthly prevalence of diarrhea was $4 \cdot 1 \%$ (95\% CI: 3·3-4.8) in Pudong, which represented an incidence rate of 0.54 (95\% CI $0.45-0.62)$ episodes of diarrhea per person-year. The estimated monthly prevalence of diarrhea varied among the age groups (Fig. 2): children $<1$ years old had the highest proportion $(11 \cdot 1 \%, 95 \%$ CI: $7 \cdot 7-14 \cdot 6)$, while adults aged 45-64 years had the lowest $(2 \cdot 5 \%, 95 \%$ CI: $1 \cdot 2-3 \cdot 8)$. The prevalence of diarrhea was higher among respondents who reported out-of-province travel history in the previous month than among those who had no travel history during that period $(4 \cdot 9 \%$ vs. $3 \cdot 8 \%$, $P<0 \cdot 001$ ) (Table 2).

Seventy-seven of the respondents who had diarrhea reported seeking healthcare during their last episode of diarrhea. The proportion of respondents with diarrhea who sought healthcare was estimated to be $21 \cdot 2 \%$ (95\% CI: 13.4-29.0) in Pudong. The healthcare-seeking proportion varied among the age groups: children aged
2-4 years had the highest proportion $(57 \cdot 6 \%, 95 \% \mathrm{CI}$ : 40.4-74.9), whereas people 25-44 years of age had the lowest $(7 \cdot 7 \%, 95 \%$ CI: $1 \cdot 4-14 \cdot 0)$ (Table 2 ).

\section{Predictors of diarrhea occurrence}

The factors affecting the occurrence of diarrhea are displayed in Table 3. Young age and travel history were significant predictors of frequent diarrhea occurrence in children less than 5 years old after adjusting for sex, average household income, education level of the children's parents/guardians and vaccination status. Rotavirus vaccination status exhibited no significant association with the occurrence of diarrhea among young children (adjusted odds ratio [aOR]: $0 \cdot 8,95 \%$ CI: $0 \cdot 5-1 \cdot 3$ ). Among older children, adolescents and adults, travel history was a significant predictor of the frequent occurrence of diarrhea after adjusting for sex, age, average household income and educational attainment of the study subjects.

\section{DISCUSSION}

This is the first population-based study of diarrhea conducted in Pudong. Over a period of 4 weeks in 


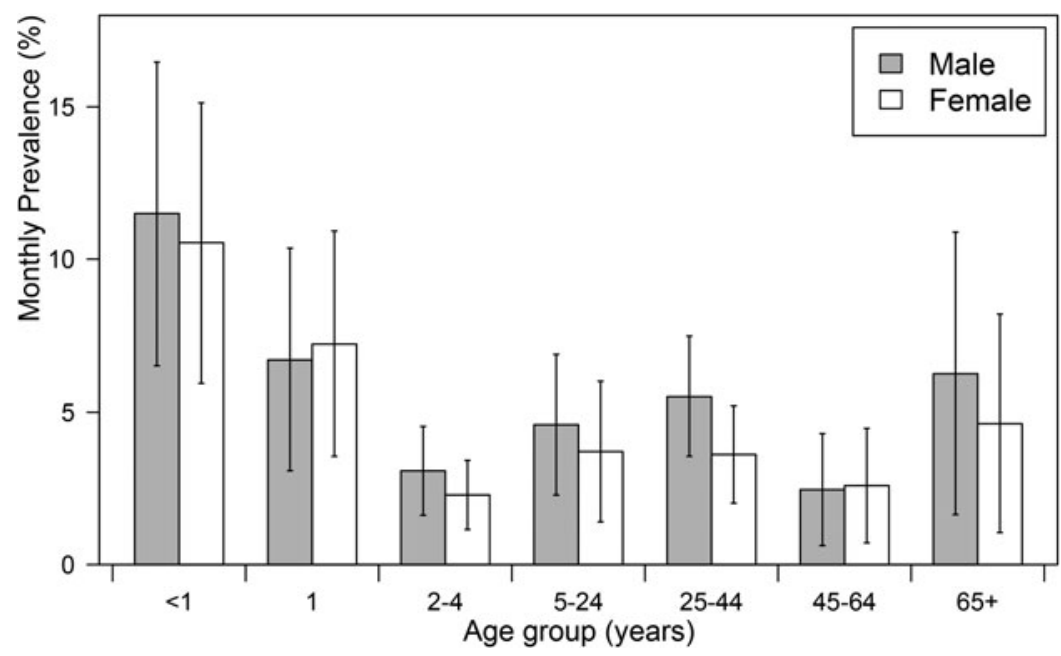

Fig. 2. Estimated monthly prevalence of diarrhea in Pudong, Shanghai, China, 2014, by age and sex.

October 2014, 5324 community-based surveys were conducted to help determine the prevalence of diarrhea and the healthcare-seeking behavior of individuals who experienced diarrhea. We found that $\approx 4$ in 100 persons reported having diarrhea in the previous month prior to the interview and that $\approx 1$ in five individuals with diarrhea reported seeking healthcare during their most recent episode of diarrhea. The estimated incidence rate of diarrhea in Pudong was 0.54 episodes per person-year, which is very close to the 2010 national estimate of 0.56 episodes per personyear [5]. These findings confirm that the rate of diarrhea has not changed substantially over the past couple of years and that the burden of diarrhea experienced by the community and healthcare facilities is substantial in Pudong.

The pooled incidence of diarrhea in the world has changed little over the past four decades (from 2.2 episodes/child-year in 1980 to 2.9 episodes/child-year in 2010) [12-15]. In our study, the overall monthly prevalence of diarrhea was $4 \cdot 1 \%(95 \%$ CI: $3 \cdot 3-4 \cdot 8)$, which is similar to the 2010 national estimates for acute gastrointestinal illness $(4 \cdot 2 \%, 95 \%$ CI: $4 \cdot 0-4 \cdot 4)$ [5]. Based on this evidence, we believe that the prevalence of diarrhea in Pudong has not changed significantly during the past couple of years. However, we noticed that the estimated monthly prevalence of diarrhea was lower in our studied population than estimates reported for some other countries, e.g., Northern Ireland and the Republic of Ireland (4.5\%) [16], England (6.5\%) [17], and the USA (5.1\%) [18]. These results should be interpreted with caution, however. The case definitions, study periods and study designs used in these studies were very different; thus, their results are not directly comparable to those of the present study. For example, Majowicz et al. noted that a different diarrhea case definition would have an impact of approximately $1 \cdot 5-2 \cdot 1$ times on the observed incidence of diarrhea [19], and Cantwell et al. observed that studies with a short recall period had a higher incidence rate than those with a longer period [20]. Additionally, the study period also influences the estimated incidence of diarrhea in cross-sectional studies, as the occurrence of diarrhea exhibits substantial seasonal variations, with a peak during the winter months for most countries according to previous studies [5, 21, 22]. The differences between the estimates in our study and others may simply reflect the different approaches the researchers adopted to study the occurrence of diarrhea. More reliable estimates of incidence rates are needed in the future, especially rates obtained from prospectively conducted active-surveillance studies.

Young children represent the population group that is most vulnerable to diarrhea. The 2010 Global Burden of Disease Study estimated that half of the deaths caused by diarrhea $(0 \cdot 7$ million deaths) were among young children $[1,4]$. The estimated monthly prevalence of diarrhea was highest among children aged $0-11$ months in our study $(11 \%)$ and was slightly increased among people aged $25-44$ years $(4 \cdot 6 \%)$. This age distribution pattern of diarrhea occurrence has also been observed in some other studies [4, 15] and can be explained by the high susceptibility of infants to infectious agents during the early ages of their life and by increased exposure to infectious agents 
Table 2. Prevalence of diarrhea and healthcare-seeking practices of respondents with diarrhea in Pudong, Shanghai, China, 2014

\begin{tabular}{|c|c|c|c|c|c|c|}
\hline Variable & \multicolumn{3}{|c|}{ Respondents who reported diarrhea $(n=231)$} & \multicolumn{3}{|c|}{ Respondents with diarrhea who sought healthcare $(n=77)$} \\
\hline Male, $n=2653$ & 125 & $4 \cdot 6(3 \cdot 5-5 \cdot 7)$ & & 42 & $21 \cdot 0(10 \cdot 4-31 \cdot 7)$ & \\
\hline Female, $n=2668$ & 106 & $3 \cdot 5(2 \cdot 5-4 \cdot 5)$ & & 35 & $21 \cdot 4(10 \cdot 0-32 \cdot 9)$ & \\
\hline Age in years & & & $<0 \cdot 001$ & & & $<0 \cdot 001$ \\
\hline$<1, n=393$ & 42 & $11 \cdot 1(7 \cdot 7-14 \cdot 6)$ & & 18 & $41 \cdot 6(25 \cdot 6-57 \cdot 5)$ & \\
\hline $5-24, n=667$ & 29 & $4 \cdot 2(2 \cdot 5-5 \cdot 8)$ & & 4 & $12 \cdot 0(0 \cdot 1-23 \cdot 9)$ & \\
\hline $25-44, n=1370$ & 59 & $4 \cdot 6(3 \cdot 3-5 \cdot 9)$ & & 7 & $7 \cdot 7(1 \cdot 4-14 \cdot 0)$ & \\
\hline $45-64, n=818$ & 18 & $2 \cdot 5(1 \cdot 2-3 \cdot 8)$ & & 8 & $44 \cdot 6(28 \cdot 1-80 \cdot 0)$ & \\
\hline$\geqslant 65, n=272$ & 15 & $5 \cdot 4(2 \cdot 5-8 \cdot 3)$ & & 5 & $45 \cdot 0(15 \cdot 7-61 \cdot 0)$ & \\
\hline Educational attainment ${ }^{1}$ & & & 0.371 & & & $<0 \cdot 001$ \\
\hline Primary school or illiterate, $n=2227$ & 93 & $2 \cdot 8(1 \cdot 6-4 \cdot 1)$ & & 46 & $40 \cdot 9(19 \cdot 8-62 \cdot 0)$ & \\
\hline High school, $n=1216$ & 47 & $4 \cdot 1(2 \cdot 7-5 \cdot 4)$ & & 11 & $32 \cdot 3(15 \cdot 3-49 \cdot 2)$ & \\
\hline College level and above, $n=1850$ & 90 & $4 \cdot 4(3 \cdot 3-5 \cdot 5)$ & & 19 & $11 \cdot 1(4 \cdot 2-18 \cdot 1)$ & \\
\hline$\geqslant 20000, n=164$ & 8 & $6 \cdot 0(0-11 \cdot 9)$ & & 4 & $6 \cdot 9(0-17 \cdot 1)$ & \\
\hline Don't know, $n=842$ & 28 & $2 \cdot 9(1 \cdot 3-4 \cdot 4)$ & & 8 & $16 \cdot 6(0-35 \cdot 3)$ & \\
\hline Travel history 1 & & & $<0.001$ & & & 0.091 \\
\hline Yes, $n=1057$ & 70 & $4 \cdot 9(3 \cdot 3-6 \cdot 5)$ & & 17 & $7 \cdot 2(0 \cdot 9-13 \cdot 4)$ & \\
\hline No, $n=4186$ & 156 & $3 \cdot 8(3 \cdot 0-4 \cdot 7)$ & & 57 & $25 \cdot 3(15 \cdot 2-35 \cdot 4)$ & \\
\hline Rotavirus vaccination ${ }^{3}$ & & & $0 \cdot 113$ & & & 0.382 \\
\hline Yes, $n=686$ & 27 & $3 \cdot 5(2 \cdot 1-5 \cdot 0)$ & & 11 & $41 \cdot 1(21 \cdot 1-61 \cdot 1)$ & \\
\hline No, $n=1460$ & 82 & $5 \cdot 8(4 \cdot 4-7 \cdot 1)$ & & 42 & $50 \cdot 8(39 \cdot 0-62 \cdot 7)$ & \\
\hline
\end{tabular}

${ }^{1}$ For children aged $<5$ years, the numbers in this column represent data for the children's parents or guardians.

${ }^{2} 1$ US dollar $\approx 6 \cdot 9$ Chinese yuan.

${ }^{3}$ History of rotavirus vaccination was collected only for children aged less than 5 years $(n=2146)$. 
Table 3. Multivariable logistic regression analysis of factors affecting the occurrence of diarrhea in Pudong, Shanghai, China, 2014, by age strata

\begin{tabular}{|c|c|c|c|c|c|}
\hline Variable & $\begin{array}{l}\text { Children aged }<5 \\
\text { years }(\mathrm{n}=2198) \\
\text { Adjusted odds ratio } \\
(95 \% \mathrm{CI})\end{array}$ & $\begin{array}{l}\mathrm{P} \\
\text { value }\end{array}$ & Variable & $\begin{array}{l}\text { Persons aged } \geqslant 5 \\
\text { years }(n=3126) \\
\text { Adjusted odds ratio } \\
(95 \% \mathrm{CI})\end{array}$ & $\begin{array}{l}P \\
\text { value }\end{array}$ \\
\hline Gender & & & Gender & & \\
\hline Male & $1 \cdot 1(0 \cdot 7-1 \cdot 6)$ & 0.912 & Male & $1 \cdot 3(0 \cdot 9-1 \cdot 9)$ & $0 \cdot 137$ \\
\hline Female & Reference & & Female & Reference & \\
\hline Age in years & & & Age in years & & \\
\hline$<1$ & $4 \cdot 5(2 \cdot 6-7 \cdot 8)$ & $<0 \cdot 001$ & $5-24$ & Reference & \\
\hline 1 & $2 \cdot 6(1 \cdot 5-4 \cdot 6)$ & $<0 \cdot 001$ & $25-44$ & $0 \cdot 8(0 \cdot 5-1 \cdot 3)$ & $0 \cdot 386$ \\
\hline $2-4$ & Reference & & $\begin{array}{l}45-64 \\
65+\end{array}$ & $\begin{array}{l}0 \cdot 4(0 \cdot 2-0 \cdot 8) \\
1 \cdot 4(0 \cdot 7-2 \cdot 8)\end{array}$ & $\begin{array}{l}0 \cdot 007 \\
0 \cdot 340\end{array}$ \\
\hline Educational attainment ${ }^{1}$ & & & Educational attainment & & \\
\hline Primary school or illiterate & Reference & & Primary school or illiterate & Reference & \\
\hline High school & $2 \cdot 1(0 \cdot 8-5 \cdot 6)$ & $0 \cdot 245$ & High school & $2 \cdot 2(1 \cdot 0-5 \cdot 1)$ & $0 \cdot 062$ \\
\hline College level and above & $2 \cdot 2(1 \cdot 2-4 \cdot 1)$ & $0 \cdot 017$ & College level and above & $2 \cdot 2(0 \cdot 9-5 \cdot 1)$ & $0 \cdot 072$ \\
\hline $\begin{array}{l}\text { Monthly average household } \\
\text { income, (Chinese yuan) })^{2}\end{array}$ & & & $\begin{array}{l}\text { Monthly average household } \\
\text { income, (Chinese yuan) }{ }^{b}\end{array}$ & & \\
\hline$<3000$ & Reference & & $<3000$ & Reference & \\
\hline 3000-9999 & $0 \cdot 8(0 \cdot 4-1 \cdot 5)$ & $0 \cdot 288$ & 3000-9999 & $0 \cdot 9(0 \cdot 5-1 \cdot 6)$ & $0 \cdot 808$ \\
\hline $10,000-19,999$ & $1 \cdot 0(0 \cdot 5-2 \cdot 1)$ & $0 \cdot 745$ & $10,000-19,999$ & $1 \cdot 4(0 \cdot 7-2 \cdot 9)$ & $0 \cdot 262$ \\
\hline$>20,000$ & $0 \cdot 7(0 \cdot 2-2 \cdot 8)$ & $0 \cdot 284$ & $>20,000$ & $1 \cdot 4(0 \cdot 4-4 \cdot 9)$ & $0 \cdot 456$ \\
\hline Don't know & $0 \cdot 6(0 \cdot 3-1 \cdot 3)$ & $0 \cdot 100$ & Don’t know & $0 \cdot 6(0 \cdot 3-1 \cdot 3)$ & $0 \cdot 586$ \\
\hline Travel history ${ }^{1}$ & & & Travel history & & \\
\hline Yes & $2 \cdot 0(1 \cdot 2-3 \cdot 3)$ & $<0 \cdot 001$ & Yes & $1 \cdot 6(1 \cdot 03-2 \cdot 4)$ & $0 \cdot 036$ \\
\hline \multirow{2}{*}{\multicolumn{6}{|c|}{ Rotavirus vaccine }} \\
\hline & & & & & \\
\hline Yes & $0 \cdot 8(0 \cdot 5-1 \cdot 3)$ & $0 \cdot 817$ & & & \\
\hline No & Reference & & & & \\
\hline
\end{tabular}

\footnotetext{
${ }^{1}$ For children aged $<5$ years, the numbers in this column represent data for the children's parents or guardians.

21 US dollar $\approx 6.9$ Chinese yuan.

Note: Estimates in bold are significant at $P<0 \cdot 05$.
}

among people aged $25-44$ years as their social life becomes more active and diverse. Although other studies have reported that the lowest prevalence of diarrhea occurs among people aged $\geqslant 65$ years $[18,23,24]$, this pattern was not observed in our study. As the sample size of study subjects who were $\geqslant 65$ years of age was slightly smaller $(n=272)$, our results relating to the elderly may be less representative than the results for other age groups. The occurrence of diarrhea reported by some other studies was higher among females than among males [5, 11, 23]. However, we did not observe a similar association in our study, which may be because most of the females in our survey were career women and only $10 \%$ of the females were housewives; thus, their risk of exposure to kitchen practices was not higher than that of men in Pudong. The association of education level with diarrhea in our study was also inconsistent with the findings of previous studies, which reported a high prevalence of diarrhea associated with low education levels [5]. We believe that this difference may be caused by our study's reliance on grandparents as interview surrogates to assess the child subjects. As most of the children's parents were at work during the day, the children in our study were cared for by their grandparents. Elderly people generally have low educational attainment, and people exhibit a larger recall bias as they age. Our results suggest that when conducting retrospective surveys involving young children, the children's mothers would be a better interview source to help minimize recall biases.

The proportion of individuals with diarrhea who reported seeking healthcare was $21 \%$ in our study. This number is much lower than the 2010 national estimate $(56 \%)$ [5], but it is very similar to estimates reported by studies conducted in some other 
developed countries, e.g., the USA (19.5\%) [18], Australia, Canada, and Ireland (19-20\%) [23]. Healthcare-seeking practices were disproportionately affected in our study by the age of the respondents and were highest among children aged $<5$ years $(42-58 \%)$. Higher levels of healthcare-seeking practices may represent a high level of severity and/or a high disease burden on healthcare facilities. Given the high rate of diarrhea occurrence and high level of healthcare practices among young children $<5$ years of age, control and prevention programs for diarrheal illness should be better targeted to this vulnerable group. In Pudong and in China, a common practice for controlling diarrhea, especially diarrhea caused by fatal cholera, is to conduct laboratorybased surveillance of diarrhea at gastrointestinal clinics. Pediatric departments/clinics are not covered by this practice, however. Since cholera cases have rarely been reported in China in recent years [25], we strongly suggest modifying national surveillance programs to include the pediatric population in future studies.

Young age $[5,11,23]$ and travel $[5,26,27]$ have been reported as risk factors for diarrhea in some previous studies. In our multivariable analysis, these factors were also significant predictors of diarrhea occurrence. Out-of-province travel in the previous month prior to the interviews was reported by $20 \cdot 2 \%$ of the respondents. This implies that each month, one in every five people in Pudong are involved in intra-provincial travel. Traveler's diarrhea should be more comprehensively addressed in the future, especially for those who travel internationally.

Interestingly, approximately $32.0 \%$ of the study respondents reported a rotavirus vaccination history for their children. This proportion was close to the value $(25 \%)$ reported by a previous study in 2012 2013 [28]. However, we did not find an association between rotavirus vaccination and the occurrence of diarrhea, although the monthly prevalence of diarrhea was lower among children with a history of rotavirus vaccination than among those with no reported vaccination history $(3 \cdot 5 \%$ vs. $5 \cdot 8 \%, P=$ $0 \cdot 113$ ). We presume that some important factors that were not measured in our study (e.g., the predominance of etiological agents during the study period) could have confounded the results. Rotavirus vaccines have been demonstrated to be efficacious in preventing rotavirus gastroenteritis and in decreasing severe disease onset (hospitalizations) in previous studies [29, 30]. However, there is no evidence that the rotavirus vaccine can reduce the overall rate of diarrhea. Other etiologic agents, e.g., norovirus, non-typhoidal Salmonella, Shigella spp., and Campylobacter spp., could also cause diarrhea. To help identify public health priorities for diarrheal illness control and prevention in Pudong, the prevalence of specific pathogens in diarrhea patients should be assessed through laboratorybased surveillance in the future.

There are some limitations to our study. First, our respondents were recruited using a convenience sampling method. This approach was employed because the response rate for the household survey was very low in our pilot study, which could have potentially affected the validity of the study. To increase the response rate, we adopted a different approach that involved interviewing community residents who were readily available at different locations, such as children's vaccination clinics, kindergartens and residential areas, where most of the population in the community gathered. This approach may introduce bias because community residents who never leave their homes or who never visit these locations during day time could not be interviewed, and children who are more likely to seek healthcare at children's vaccination clinics would be oversampled even though the overall coverage rate of the clinics for children eligible for immunization was estimated at $99 \%$ in 2014 [31]. To help increase the representativeness of the study data, the surveys of children and adults were conducted separately and population weights were applied to adjust for the complex sampling procedures in the study. Second, our study was conducted in October in autumn. Since diarrheal diseases tend to peak during winter months in most countries, the calculated prevalence of diarrhea in our study might be underestimated. Third, recall bias was an important issue in our study; for example, 'telescoping bias' may have led to an overestimation of the frequency of diarrhea in our study. Fourth, we did not collect data on the proportion of diarrheal patients who submitted a stool sample for pathogen testing in the study, which would potentially hamper the allocation of resources to public health laboratories that conducted surveillance for diarrhea at Pudong. Finally, the travel history and educational attainment of child subjects $<5$ years of age were not collected; instead, we collected data for the individuals who responded on behalf of those children (parents/guardians). Whether the child subjects had travelled with their parents/guardians was not recorded in our 
study. However, our results confirm that the travel history of parents/guardians also has an effect on the occurrence of diarrhea among young children. Avoiding close contacts with young children or practicing better hygiene following recent travel could help prevent diarrhea in children.

\section{CONCLUSIONS}

In summary, the population in Pudong remains at frequent risk for diarrhea, and diarrhea continues to impose a considerable burden on the community and the healthcare system. Young children are the most vulnerable group, and diarrhea control and prevention programs, e.g., laboratory-based surveillance, should be modified to include this high-risk group.

\section{ACKNOWLEDGEMENTS}

We wish to thank the community health workers working in the 46 community health centers of Pudong for their enthusiasm and diligence in carrying out the interviews and the community respondents for their cooperation. This work was supported by the Ministry of Science and Technology of the People's Republic of China funded program, the National Key Science and Technology Project on Infectious Disease Surveillance Technique Platform of China [2012ZX10004201], and by the key discipline construction of health system project in Pudong New Area [No.PWzx2014-14].

\section{DECLARATION OF INTEREST}

None.

\section{ETHICAL STANDARDS}

The authors assert that all procedures contributing to this work comply with the ethical standards of the relevant national and institutional committees on human experimentation and with the Helsinki Declaration of 1975, as revised in 2008. Ethical approval was obtained from Shanghai Pudong New Area Center for Disease Control and Prevention Review Board. Written and informed consent was obtained from all the participants or from the parents/guardians of child subjects before the interviews. The participants' information was anonymized and de-identified prior to analysis.

\section{REFERENCES}

1. Lozano R, et al. Global and regional mortality from 235 causes of death for 20 age groups in 1990 and 2010: a systematic analysis for the Global Burden of Disease Study 2010. The Lancet 2012; 380(9859): 2095-2128.

2. Murray CJ, et al. Disability-adjusted life years (DALYs) for 291 diseases and injuries in 21 regions, 1990-2010: a systematic analysis for the Global Burden of Disease Study 2010. The Lancet 2012; 380(9859): 2197-2223.

3. World Health Organization. The United Nations Fourth Millennium Development Goals (http://www.who.int/ topics/millennium_development_goals/child_mortality/ en/). Accessed 28 March 2017.

4. Walker CL, et al. Global burden of childhood pneumonia and diarrhoea. The Lancet 2013; 381(9875): 1405 1416.

5. Chen Y, et al. Burden of self-reported acute gastrointestinal illness in China: a population-based survey. BMC Public Health 2013; 13: 456.

6. Chen S, Zhang J. Shanghai Pudong New Area Statistical Yearbook. China Statistics Press, Beijing, China. 2015, p. 321.

7. Bresee J, Biritwum RB. Generic protocols for (i) hospitalbased surveillance to estimate the burden of rotavirus gastroenteritis in children and (ii) a community-based survey on utilization of health care services for gastroenteritis in children. In: Document WHO/V\&B/0215. Geneva: World Health Organization, 2002, pp. 45-67.

8. Yu J, et al. Etiology of diarrhea among children under the age five in China: results from a five-year surveillance. Journal of Infection 2015; 71(1): 19-27.

9. R Core Team. A Language and Environment for Statistical Computing. Vienna, Austria: R Foundation for Statistical Computing, 2013.

10. Lumley T. Complex Surveys: A Guide to Analysis using R. John Wiley \& Sons, Hoboken, New Jersey. 2011.

11. Thomas MK, et al. Population distribution and burden of acute gastrointestinal illness in British Columbia, Canada. BMC Public Health 2006; 6: 307.

12. Snyder JD, Merson MH. The magnitude of the global problem of acute diarrhoeal disease: a review of active surveillance data. Bulletin of the World Health Organization 1982; 60(4): 605.

13. Bern C, et al. The magnitude of the global problem of diarrhoeal disease: a ten-year update. Bulletin of the World Health Organization 1992; 70(6): 705-714.

14. Kosek M, Bern C, Guerrant RL. The global burden of diarrhoeal disease, as estimated from studies published between 1992 and 2000. Bulletin of the World Health Organization 2003; 81(3): 197-204.

15. Fischer Walker CL, et al. Diarrhea incidence in lowand middle-income countries in 1990 and 2010: a systematic review. BMC Public Health 2012; 12: 220.

16. Scallan E, et al. Acute gastroenteritis in northern Ireland and the Republic of Ireland: a telephone survey. Communicable Disease and Public Health/PHLS 2004; 7 (1): 61-67.

17. Wheeler JG, et al. Study of infectious intestinal disease in England: rates in the community, presenting to 
general practice, and reported to national surveillance. The Infectious Intestinal Disease Study Executive. BMJ 1999; 318(7190): 1046-1050.

18. Jones TF, et al. A population-based estimate of the substantial burden of diarrhoeal disease in the United States; FoodNet, 1996-2003. Epidemiology and Infection 2007; 135(2): 293-301.

19. Majowicz S, et al. A common, symptom-based case definition for gastroenteritis. Epidemiology and Infection 2008; 136(7): 886-894.

20. Cantwell LB, et al. The effect of different recall periods on estimates of acute gastroenteritis in the United States, FoodNet Population Survey 2006-2007. Foodborne Pathogens and Disease 2010; 7(10): 1225-1228.

21. de Wit MA, et al. Sensor, a population-based cohort study on gastroenteritis in the Netherlands: incidence and etiology. American Journal of Epidemiology 2001; 154(7): 666-674.

22. Roy SL, Scallan E, Beach MJ. The rate of acute gastrointestinal illness in developed countries. Journal of Water and Health 2006; 4(Suppl. 2): 31-69.

23. Scallan E, et al. Prevalence of diarrhoea in the community in Australia, Canada, Ireland, and the United States. International Journal of Epidemiology 2005; 34 (2): 454-460.

24. Tam CC, et al. The second study of infectious intestinal disease (IID2): increased rates of recurrent diarrhoea in individuals aged 65 years and above. BMC Public Health 2013; 13(1): 1-8.

25. Yang G, et al. Rapid health transition in China, 1990 2010: findings from the Global Burden of Disease Study 2010. The Lancet 2013; 381(9882): 1987-2015.

26. Vrbova $\mathbf{L}$, et al. A descriptive study of reportable gastrointestinal illnesses in Ontario, Canada, from 2007 to 2009. BMC Public Health 2012; 12: 970.

27. Kuusi M, et al. Incidence of gastroenteritis in Norway a population-based survey. Epidemiology and Infection 2003; 131(1): 591-597.

28. Yi F, et al. Study on the prevalence and determinants of viral diarrhea among children aged under five years in Pudong New Area. Chinese Journal of Disease Control \& Prevention 2014; 18(1): $44-47$ (in Chinese).

29. Vesikari T, et al. Safety and efficacy of a pentavalent human-bovine (WC3) reassortant rotavirus vaccine. New England Journal of Medicine 2006; 354(1): 23-33.

30. Ruiz-Palacios GM, et al. Safety and efficacy of an attenuated vaccine against severe rotavirus gastroenteritis. New England Journal of Medicine 2006; 354(1): $11-22$.

31. Shanghai Municipal Commission of Health and Family Planning. The coverage rate of children immunization in shanghai (http://www.wsjsw.gov.cn/wsj/n429/n432/ n1488/n1490/u1ai141465.html). Accessed 30 June 2017 (in Chinese). 